\title{
The influence of geomagnetic storms on the estimation of GPS instrumental biases
}

\author{
W. Zhang, D. H. Zhang, and Z. Xiao \\ The Department of Geophysics, Peking University, China
}

Received: 10 October 2008 - Revised: 2 February 2009 - Accepted: 18 February 2009 - Published: 3 April 2009

\begin{abstract}
An algorithm has been developed to derive the ionospheric total electron content (TEC) and to estimate the resulting instrumental biases in Global Positioning System (GPS) data from measurements made with a single receiver. The algorithm assumes that the TEC is identical at any point within a mesh and that the GPS instrumental biases do not vary within a day. We present some results obtained using the algorithm and a study of the characteristics of the instrumental biases during active geomagnetic periods. The deviations of the TEC during an ionospheric storm (induced by a geomagnetic storm), compared to the quiet ionosphere, typically result in severe fluctuations in the derived GPS instrumental biases. Based on the analysis of three ionospheric storm events, we conclude that different kinds of ionospheric storms have differing influences on the measured biases of GPS satellites and receivers. We find that the duration of severe ionospheric storms is the critical factor that adversely impacts the estimation of GPS instrumental biases. Large deviations in the TEC can produce inaccuracies in the estimation of GPS instrumental biases for the satellites that pass over the receiver during that period. We also present a semi quantitative analysis of the duration of the influence of the storm.
\end{abstract}

Keywords. Ionosphere (Ionospheric disturbances; Midlatitude ionosphere) - Radio science (Ionospheric physics)

\section{Introduction}

The Global Positioning System (GPS) is a useful tool for measuring the ionospheric total electron content (TEC). Dual-frequency GPS receiver provides both carrier phases and pseudo-ranges measurements for two frequencies

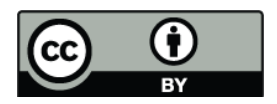

Correspondence to: D. H. Zhang

(zhangdh@pku.edu.cn)
( $\mathrm{f} 1=1575.42 \mathrm{MHz}$ and $\mathrm{f} 2=1227.60 \mathrm{MHz}$ ), and these can be used to derive the ionospheric delays. The measured differential delays, however, contain not only the delay resulting from the ionospheric TEC, but also the delay generated by the instrumental biases of the GPS satellites and receivers. To obtain accurate estimates of the ionospheric TEC the differential instrumental biases must be removed. Accurately determining these instrumental biases represents the main source of error in the estimation of TEC using GPS data. Many methods for estimating the ionospheric TEC have been published (e.g., Coco et al., 1991; Lanyi and Roth, 1988; Liu and Gao, 2004; Ma and Maruyama, 2003; Otsuka et al., 2002; Sardón and Zarraoa, 1997). They all involve approximations such as representing the whole ionosphere by a spherical layer of infinitesimal thickness, neglecting the horizontal gradients in the electron density distribution, etc. Some studies test the accuracy of the models' measurement of the TEC through comparison with direct ionospheric measurements using radar, satellite or accepted models to verify their approximations (Brunini et al., 2005; Ho et al., 1997; Otsuka et al., 2002; Vladimer et al., 1997). Applications of TEC measurements include ionospheric mapping (Wilson et al., 1995), detection of plasma irregularities (Mendillo et al., 2000; Nishioka et al., 2008) and observations of natural and man-made disturbed effects in the ionosphere, such as flare (Zhang and Xiao, 2003, 2005), earthquake (Ducic et al., 2003), and space shuttle flight (Calais and Minster, 1996).

Only a small number of GPS receivers have the facility to determine differential instrumental biases through internal calibration. For satellites, although pre-launch calibration is undertaken, the values through internal calibration show poor agreement with the later values estimated from observations (Coco et al., 1991). Therefore, methods to estimate instrumental biases are necessary to obtain accurate estimates of the ionospheric TEC from GPS data. Furthermore, nearly all of the methods used to estimate the TEC assume smooth spatial and temporal variations in the ionospheric

Published by Copernicus Publications on behalf of the European Geosciences Union. 
behaviour over the observation area during the time interval. In other words, the TEC is assumed as uniform over small areas during certain time interval (Chang et al., 2001; Coco et al., 1991; Lanyi and Roth, 1988; Liu and Gao, 2004; Sardón and Zarraoa, 1997; Ma and Maruyama, 2003; Otsuka et al., 2002; Wilson et al., 1995). This assumption is not always valid, especially in certain areas of great ionospheric interest, such as the equatorial and auroral zones (due to latitude effects) and during geomagnetic storms, where enhanced solar winds and/or interplanetary magnetic fields induce large and dramatic global disturbances in the ionosphere and thermosphere. The disturbed ionosphere manifests as huge increases and/or depletions in the electron density when compared to normal levels - this is known as an ionospheric storm. Over the past ten years numerous and extensive studies have focused on the morphology and mechanisms of ionospheric storms based on the ionospheric TEC derived from GPS data and have revealed some features of the global and local evolution of storms (Araujo-Pradere et al., 2002a, b, 2004; Buonsanto, 1999; Goncharenko et al., 2007; Liu et al., 2004; Prolss, 1995; Mendillo, 2006; Yizengaw et al., 2005). In the meantime, the techniques to estimate the instrumental bias using GPS observation data have been developed and the problems concerning the precision of the estimated bias and TEC results have been also studied (Bishop et al., 1996; Coco et al., 1991; Lanyi and Roth, 1988; Ma and Maruyama, 2003; Sardón and Zarraoa, 1997). Despite this, little attention has been paid on the influence of GPS instrumental biases themselves on TEC measurements during geomagnetic active period.

In this paper we investigate the influence of geomagnetic storms on the estimation of GPS instrumental biases and develop a method for deriving the TEC and understanding the potential effects of space weather by using the GPS data from three sites within China, PKU0 $\left(39.99^{\circ} \mathrm{N}, 116.31^{\circ} \mathrm{E}\right)$, BJFS $\left(39.61^{\circ} \mathrm{N}, 115.89^{\circ} \mathrm{E}\right)$ and GUAO $\left(43.47^{\circ} \mathrm{N}, 87.18^{\circ} \mathrm{E}\right)$. These stations are all located at middle latitudes where the ionosphere is thought to be free from the influences of the composition disturbance zone (Prolss, 1995) and equatorial anomalies (i.e., there should be no latitude-dependent effects). Our study focuses on investigating the deviations in the derived instrumental biases that occur on days when there are ionospheric storms. The ionospheric delay model determined from dual-frequency GPS signals and the estimation method are described in Sect. 2. In Sect. 3, we present the results as applied to three events. Section 4 discusses our results and presents the conclusions of the study.

\section{Algorithm for determination of GPS instrumental biases}

\subsection{TEC extraction from GPS observation}

The ionosphere is a dispersive medium and the electromagnetic wave propagating through it suffers a range delay whose magnitude depends on the amount of TEC and the frequency of the wave. Concerning to the GPS L-band waves, the range delay (in meter) can be expressed as:

$\Delta R= \pm \frac{k S T E C}{2 f^{2}}$,

where $k=80.62 \mathrm{em}^{3} \mathrm{~s}^{-2}, f$ is the frequency of the wave (the unit is $\mathrm{Hz}$ ). The $S T E C$ is the integrated electron density along the line from GPS satellite to receiver and can be obtained from the pseudo-ranges or the carrier phase advances of two different frequencies from the following equations

$$
\begin{aligned}
& \text { STEC }^{p}=\frac{2\left(f_{1} f_{2}\right)^{2}}{k\left(f_{1}^{2}-f_{2}^{2}\right)}\left(P_{2}-P_{1}\right), \\
& \text { STEC }^{l}=-\frac{2\left(f_{1} f_{2}\right)^{2}}{k\left(f_{1}^{2}-f_{2}^{2}\right)}\left(L_{2} \lambda_{2}-L_{1} \lambda_{1}\right),
\end{aligned}
$$

where $\lambda_{1}$ and $\lambda_{2}$ are the wavelengths (the units are $\mathrm{m}$ ), $P_{1}$ and $P_{2}$ are the pseudo-ranges (the units are $\mathrm{m}$ ), $L_{1}$ and $L_{2}$ are the carrier phases and $f_{1}$ and $f_{2}$ are the frequencies of the two GPS signals, respectively. The unit of the STEC in above equations is $1 \mathrm{e} / \mathrm{m}^{2}$. There is potential ambiguity in the carrier phase advances measurement, and because of this $S T E C^{l}$ is a relative value. However, the measurement of $S T E C^{l}$ has higher precision than $S T E C^{p}$ by a factor of 100 or more (Wells et al., 1986). This potential ambiguity is simply the offset between the pseudo-ranges measurements and the carrier phase measurements. To obtain a more accurate slant path TEC, these two measurement types can be combined by fitting $S T E C^{l}$ measurement to $S T E C^{p}$ measurement, and a baseline $B_{r s}$ is introduced (Ciraolo et al., 2007; Horvath and Essex, 2000; Mannucci et al., 1998)

$$
\begin{aligned}
& S T E C=S T E C^{l}+B_{r s}, \\
& B_{r s}=\frac{\sum_{k=1}^{N}\left(S T E C_{k}^{p}-S T E C_{k}^{l}\right) \sin ^{2} e l_{k}}{\sum_{k=1}^{N} \sin ^{2} e l_{k}},
\end{aligned}
$$

where $N$ denotes the number of observation epochs along a continuous tracking arc under investigation. The baseline $B_{r s}$ in the paper is referred to the average difference between pseudo-range-derived $\mathrm{TEC}^{p}$ and carrier-phase-derived $\mathrm{TEC}^{l}$ over the index $i$ from 1 to $N$ inclusive. The $\sin ^{2} e l_{k}$ term (where $e l_{k}$ is the satellite's elevation) is a weighting factor that reduces the multipath effect and improves the reliability of the method at low elevations in that the pseudo-range 
with low elevation angle is apt to be affected by multipath effect and the reliability decreases. Thus, the contribution to baseline determination is greatly depleted with low elevations. In the meanwhile, our results (not shown here) demonstrate that this method with the pseudo-range-levelled carrier phases is free of ambiguities and also has lower noise than that with pseudo-ranges. It should be mentioned that the continuous tracking arc in this paper is always locked. To ensure the quality of the GPS data when estimating the instrumental bias, the satellite elevation must be greater than 30 degrees, when cycle slip events seldom occur. Despite this, if a cycle slip occurs in a continuous satellite-receiver pair observation, the discontinuous tracking arc after the cycle slip can be considered as a separate continuous arc from which a different offset $B_{r s}$ can be calculated using Eq. (5). While deriving the ionospheric TEC based on the raw GPS data, the instrumental bias generated by interior electronic circuits of the GPS satellite and receiver should be removed. Considering the geometry of the satellite, receiver, and ionosphere, the vertical TEC at the ionospheric piercing point that is the intersection point between the ionospheric thin shell (assumed to be $400 \mathrm{~km}$ in this paper) and the line of sight from satellite to receiver can be calculated using following formula:

$V T E C=\left(S T E C-B_{s}-B_{r}\right) \cos E_{\text {ion }}$.

$B_{s}$ and $B_{r}$ are the satellite and receiver instrumental biases, respectively. The $\cos E_{\text {ion }}$ is a vertical TEC mapping function and $E_{\text {ion }}$ can be obtained from Eq. (7):

$E_{\text {ion }}=\arcsin \left(\frac{R_{E}}{R_{E}+H_{i}} \cos e l\right)$,

where $e l$ is the satellite elevation, $R_{E}$ is the radius of the Earth, and $H_{i}$ is the height of the assumed ionospheric thin shell.

\subsection{Determination of instrumental biases}

The instrumental biases and vertical TEC were determined using the self-calibration of pseudo-range errors (SCORE) process (Bishop et al., 1996), whose concepts and assumptions are widely accepted. An important concept in the SCORE process is that of a "conjunction" between two satellites. A conjunction is observed when two satellites arrive at a certain area in the height of the ionosphere at the same moment. When this occurs it is assumed that the same vertical TEC should be measured from each satellite. In this paper, the configuration used for the definition of near conjunction is 0.5 degrees in latitude by $0.1 \mathrm{~h}$ in local time. $\operatorname{STEC}_{\alpha i}\left(\theta_{\alpha i}\right.$, $\tau_{\alpha i}$ ) denotes the slant TEC associated with the ionosphere penetrated by the line of GPS satellite $\alpha$ and receiver $i$, where $\theta$ and $\tau$ represent latitude and local time. In addition, $\beta$ in these equations is the other GPS satellite in the conjugate pair. Using the assumption outlined above, we can write the following equation

$\left(S T E C_{\alpha i}-B_{\alpha}-B_{i}\right) \cos E_{\text {ion } \alpha \mathrm{i}}=$

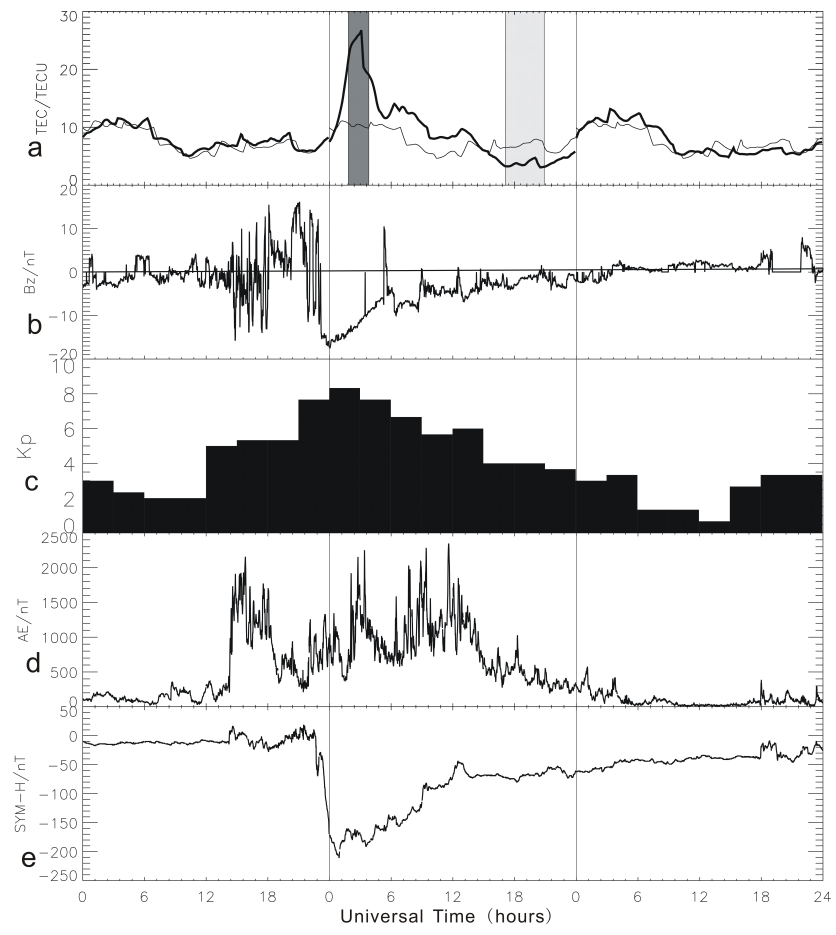

Fig. 1. (a) vertical TEC over PKU0 station on 14-16 December (days 348-350) 2006 (bold line) and that on 5 December (day 339) 2006 (slim line). The darker shaded patch indicates the more than $100 \%$ increase positive phase of the storm, and the lighter shaded patch indicates the more than $50 \%$ decrease negative phase of the storm. (b) interplanetary magnetic field $B_{z}$, (c) $K_{p}$ index, (d) $\mathrm{AE}$ index, (e) $\mathrm{H}$ component of symmetric disturbance index on 14-16 December (days 348-350) 2006.

$$
\left(S_{E T C} C_{\beta i}-B_{\beta}-B_{i}\right) \cos E_{\mathrm{ion} \beta \mathrm{i}},
$$

which transforms to

$$
\begin{gathered}
\cos E_{\mathrm{ion} \beta \mathrm{i}}\left(B_{\beta}+B_{i}\right)-\cos E_{\mathrm{ion} \alpha \mathrm{i}}\left(B_{\alpha}+B_{i}\right)= \\
S T E C_{\beta i} \cos E_{\mathrm{ion} \beta \mathrm{i}}-S T E C_{\alpha i} \cos E_{\mathrm{ion} \alpha \mathrm{i}} .
\end{gathered}
$$

The unknowns can be estimated by solving the following set of equations, which can be expressed in matrix form as

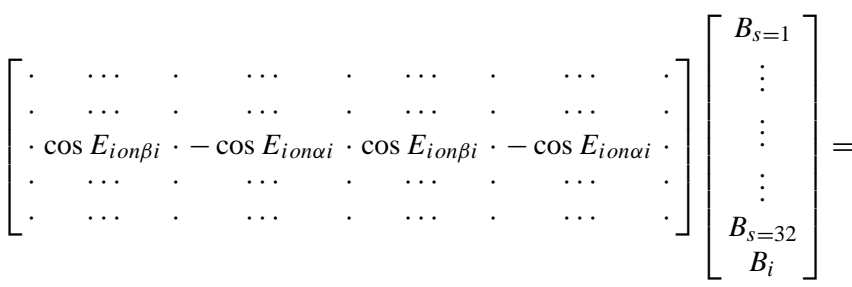

$$
\begin{aligned}
& {\left[\begin{array}{c}
\cdots \\
\cdots \\
S T E C_{\beta i} \cos E_{\text {ion } \beta i}-S T E C_{\alpha i} \cos E_{\text {ion } \alpha i} \\
\cdots \\
\cdots
\end{array}\right] .}
\end{aligned}
$$

The solution to the above set of equations can be obtained using singular value decomposition, which avoids unrealistic 


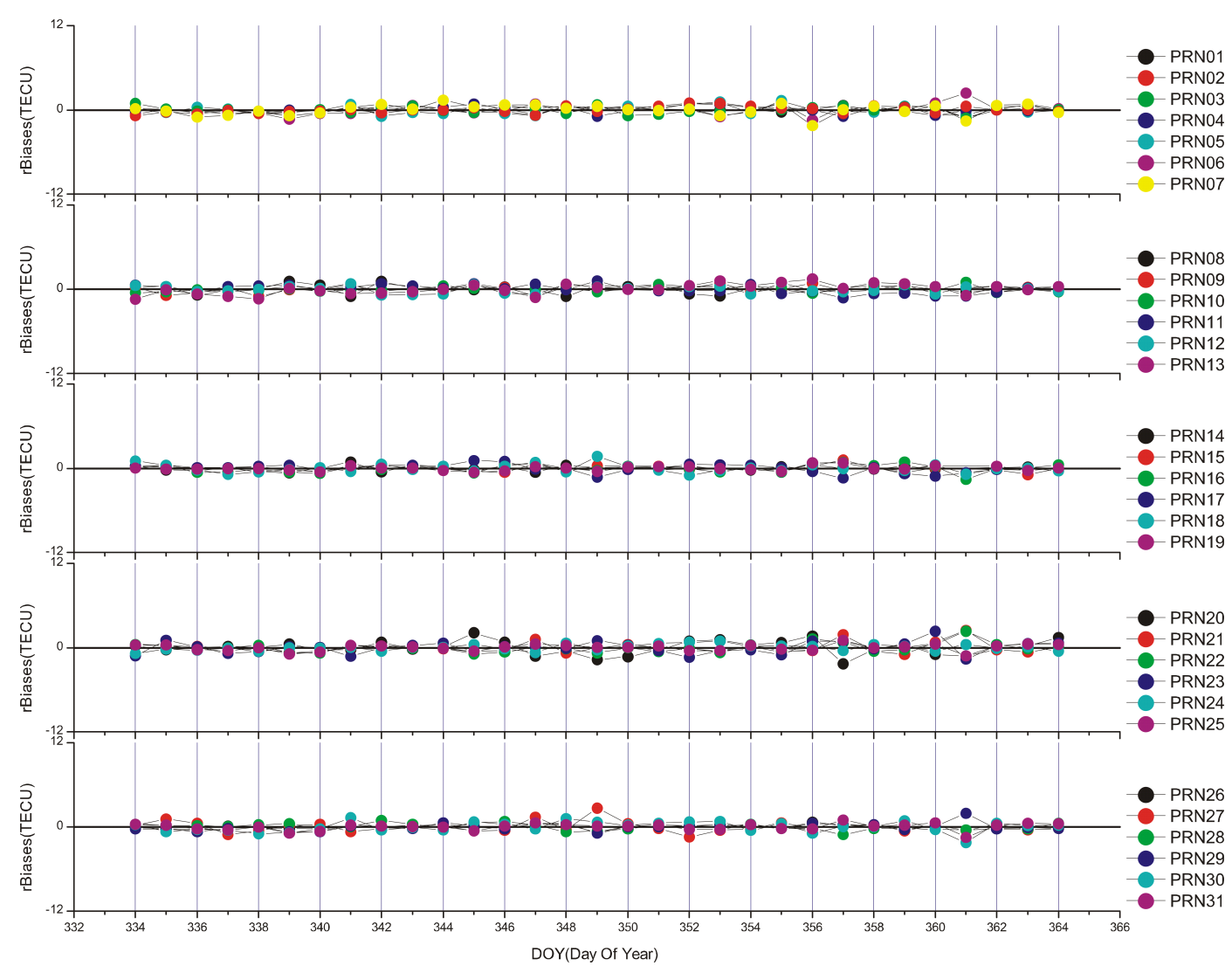

Fig. 2. The deviations in the instrumental biases derived from PKU0 relative to the mean (in TECU) from 30 November to 30 December (days 334-364) 2006. They are divided into some panels to show the results clearly.

solutions of the equation system (Press et al., 1992). The SCORE process uses $24 \mathrm{~h}$ of data from a single receiver, and it is assumed that the satellite and receiver biases do not vary throughout the day.

\section{Results}

\subsection{The event of 15 December (day 349) 2006}

The first ionospheric storm event under consideration occurred on 15 December 2006. Figure 1 shows a summary of the magnetic conditions: the derived vertical TEC (in TECU, 1 TECU $\left.=10^{16} \mathrm{e} / \mathrm{m}^{2}\right)$ over PKU0 station $\left(39.99^{\circ} \mathrm{N}\right.$, $116.31^{\circ} \mathrm{E}$ ), the interplanetary magnetic field $B_{z}$, the $K_{p}$ index, the AE (Auroral Electrojet) index, and the SYM-H (H component of symmetric disturbance index) index over the period 14-16 December 2006. A shock was detected at 13:40 UT (not shown in this paper) on 14 December at the WIND satellite location, which observed an abrupt increase in the solar wind speed. Subsequent to the shock, the $B_{z}$ component (Fig. 1b) commenced oscillations that continued for a few hours. The AE index (Fig. 1d) shows that auroral electrojet activity increased in strength after the arrival of the shock, and continued to be strong until 15:00 UT on 15 December. After 18:00 UT on 14 December, $B_{z}$ was directed northward and continued to undergo rapid oscillations before its rapid southward turning at 23:00 UT on 14 December. Figure 1e shows that the longitudinally symmetric (SYM-H) disturbance indices dropped to $-211 \mathrm{nT}$ at 01:00 UT on 15 December, and then started to recover. We have used the SYM-H index instead of the disturbance storm time $\left(D_{s t}\right)$ index, since its $1 \mathrm{~min}$ time resolution is more appropriate for studying short timescale phenomena. The SYM-H index follows essentially the same variations as the Dst index, although it is obtained from a different set of stations and uses a different coordinate system (Iyemori and Rao, 1996). The $K_{p}$ index (Fig. 1c) shows that intense activity occurred on 15 December, reaching values of $8+$ in the time range 00:00-03:00 UT. We have used the ionospheric parameters on 5 December as the quiet time reference, as the $K_{p}$ and $\mathrm{AE}$ index were quite low on that day.

The TECs derived from GPS observations at the PKU0 station over the period 14-16 December 2006 are plotted with bold lines in Fig. 1a. For the purpose of comparison, the TEC for a quiet day (5 December) are plotted with a slim line in the same figure. The appearance of obvious TEC enhancements (i.e. a positive storm phase) started at 01:00 UT 
Table 1. The MEAN, RMS (Root Mean Square Value) and the difference between rBias and RMS of 31 GPS satellites in the event of 15 December (day 349) 2006. The PRN column gives the number of the GPS satellite, and the MEAN column gives the median value of instrumental biases.

\begin{tabular}{|c|c|c|c|}
\hline PRN & $\begin{array}{r}\text { MEAN } \\
(\mathrm{TECU})\end{array}$ & $\begin{array}{r}\text { RMS } \\
(\mathrm{TECU})\end{array}$ & $\begin{array}{r}\text { rBias-RMS } \\
(\mathrm{TECU})\end{array}$ \\
\hline 1 & 8.23 & 0.42 & -0.34 \\
\hline 2 & -16.16 & 0.46 & -0.20 \\
\hline 3 & 7.81 & 0.48 & 0.23 \\
\hline 4 & 3.75 & 0.44 & 0.46 \\
\hline 5 & 7.61 & 0.56 & -0.42 \\
\hline 6 & 5.85 & 0.75 & -0.41 \\
\hline 7 & 11.05 & 0.77 & -0.29 \\
\hline 8 & 9.44 & 0.55 & 0.01 \\
\hline 9 & 4.82 & 0.47 & -0.17 \\
\hline 10 & 11.03 & 0.36 & 0.00 \\
\hline 11 & -5.61 & 0.58 & 0.62 \\
\hline 12 & -7.21 & 0.52 & -0.20 \\
\hline 13 & -5.13 & 0.73 & -0.51 \\
\hline 14 & -2.41 & 0.34 & -0.24 \\
\hline 15 & 10.74 & 0.42 & -0.04 \\
\hline 16 & -2.70 & 0.54 & -0.27 \\
\hline 17 & -3.26 & 0.58 & 0.69 \\
\hline 18 & -3.00 & 0.33 & 0.10 \\
\hline 19 & -11.00 & 0.57 & 1.16 \\
\hline 20 & 4.04 & 0.98 & 0.70 \\
\hline 21 & -5.68 & 0.74 & -0.66 \\
\hline 22 & -17.41 & 0.66 & 0.11 \\
\hline 23 & -24.29 & 0.85 & 0.14 \\
\hline 24 & 13.30 & 0.44 & -0.12 \\
\hline 25 & 1.33 & 0.46 & -0.45 \\
\hline 26 & 3.69 & 0.26 & 0.45 \\
\hline 27 & 7.55 & 0.77 & 1.90 \\
\hline 28 & -3.12 & 0.45 & 0.19 \\
\hline 29 & 3.82 & 0.52 & 0.36 \\
\hline 30 & 0.41 & 0.73 & -0.09 \\
\hline 31 & -9.32 & 0.49 & -0.36 \\
\hline
\end{tabular}

and lasted for $12 \mathrm{~h}$. The period of the more than $100 \%$ increase positive storm phase (regarded as a severe positive storm) between 01:45 UT and 04:00 UT on 15 December is marked by the darker shaded patch in Fig. 1a, and that of the more than $50 \%$ decrease negative storm phase (regarded as a severe negative storm) is indicated by the region of lighter shading.

In order to show the variation of the instrumental bias estimated from GPS observation on different days, the deviations of the instrumental biases (rBias) that means the difference between the satellite instrumental delay estimated for the event day and the mean of the instrumental delays for the period of 31 days around the event day are calculated. Figure 2 shows the deviations in the instrumental biases derived from PKU0 relative to the mean (in TECU) from 30
Table 2. The MEAN, RMS (Root Mean Square Value) and the difference between rBias and RMS of 29 GPS satellites in the event of 24 August (day 236) 2005. The PRN column gives the number of the GPS satellite, and the MEAN column gives the median value of instrumental biases.

\begin{tabular}{|c|c|c|c|}
\hline PRN & $\begin{array}{r}\text { MEAN } \\
\text { (TECU) }\end{array}$ & $\begin{array}{r}\text { RMS } \\
(\mathrm{TECU})\end{array}$ & $\begin{array}{r}\text { rBias-RMS } \\
(\mathrm{TECU})\end{array}$ \\
\hline 1 & 8.03 & 0.73 & 0.88 \\
\hline 2 & -16.96 & 0.37 & 0.54 \\
\hline 3 & 7.19 & 1.00 & -0.66 \\
\hline 4 & 3.48 & 0.33 & 0.11 \\
\hline 5 & 6.03 & 0.57 & 0.41 \\
\hline 6 & 5.20 & 0.73 & 0.64 \\
\hline 7 & 12.00 & 0.35 & 0.62 \\
\hline 8 & 8.68 & 0.58 & 1.80 \\
\hline 9 & 3.19 & 0.65 & 1.51 \\
\hline 10 & 10.39 & 0.50 & 0.93 \\
\hline 11 & -5.73 & 1.87 & 5.61 \\
\hline 13 & -5.13 & 0.46 & 0.81 \\
\hline 14 & -3.12 & 0.61 & 1.06 \\
\hline 15 & 8.72 & 0.55 & 1.34 \\
\hline 16 & -1.08 & 0.64 & 1.39 \\
\hline 18 & -5.07 & 0.52 & 1.33 \\
\hline 19 & -10.68 & 0.92 & -0.78 \\
\hline 20 & 2.67 & 0.96 & 0.58 \\
\hline 21 & -7.94 & 0.61 & 1.33 \\
\hline 22 & -19.42 & 0.57 & 1.41 \\
\hline 23 & -23.81 & 0.53 & -0.42 \\
\hline 24 & 13.95 & 0.56 & 1.84 \\
\hline 25 & 0.73 & 0.68 & 0.68 \\
\hline 26 & 2.29 & 0.86 & 1.00 \\
\hline 27 & 6.82 & 0.59 & 1.21 \\
\hline 28 & -4.47 & 0.75 & 2.63 \\
\hline 29 & 1.44 & 0.84 & -0.03 \\
\hline 30 & -2.00 & 0.59 & -0.53 \\
\hline 31 & 4.59 & 0.71 & 2.44 \\
\hline
\end{tabular}

November to 30 December (days 334-364) 2006 as a function of the day of the year (DOY). The median values of the biases are evaluated from the 31 days of results centred on 15 December 2006 (the primary date of interest here). The scale is the same for all the satellites and the $y$-axis range is from -12 TECU to 12 TECU, and the figure is separated into several panels to show the results clearly. The deviations on day 349 are much larger than average for most of the satellites. The specific differences between the rBias and RMS (Root Mean Square Value) are shown in Table 1. There are a small number of other days (such as days 357 and 361), which also show larger deviations; however, this is because of missing data for these days: these days do not have a significant impact on our statistical results or the results on the day under investigation (the storm day).

Figure 3 shows the temporal TEC (in TECU) variation curves derived from observations from the PKU0 receiver in 


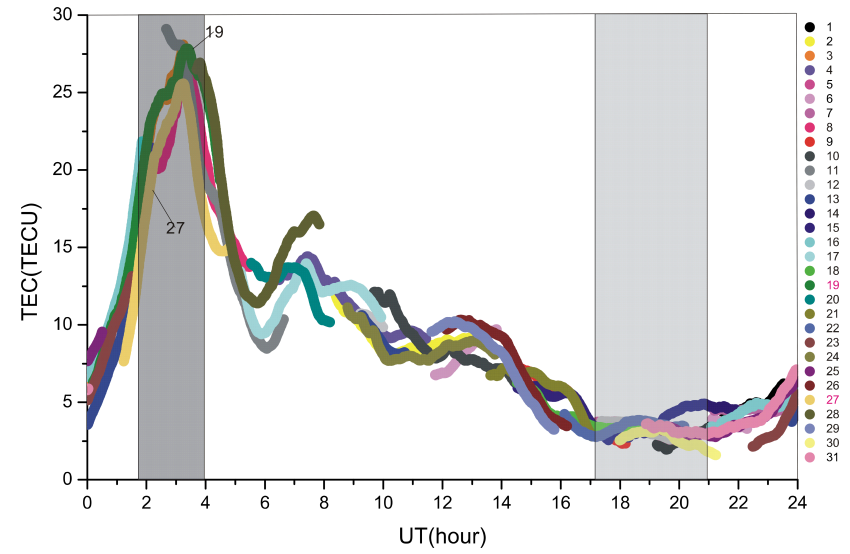

Fig. 3. The temporal TEC variation curves of all the GPS satellites from the PKU0 receiver in the period of the ionospheric storm on 15 December 2006.

the period of the ionospheric storm on 15 December 2006. The PRN with corresponding values for the difference between the rBias and RMS greater than 1 TECU are indicated by pink numbers in the legend. The time ranges with darker and lighter shading are the same as those in Fig. 1a. It can be seen that most of the bias results where the GPS satellites deviate significantly are within the darker shaded time range.

\subsection{The event of 24 August (day 236) 2005}

Figure 4 shows the derived vertical TEC (in TECU) over the GUAO station $\left(43.47^{\circ} \mathrm{N}, 87.18^{\circ} \mathrm{E}\right)$ (Fig. 4a), the interplanetary magnetic field $B_{z}$ (Fig. 4b), the $K_{p}$ index (Fig. 4c), the AE index (Fig. 4d), and the SYM-H index (Fig. 4e) over the period 23-25 August 2005. Figure 4a shows that the period of the positive and negative storm phase are between 03:30 UT and 14:30 UT and between 17:00 UT and 23:59 UT on 24 August, respectively. The more than 100\% increase positive storm phase is indicated by the darker shaded region and the more than $50 \%$ decrease negative phase by the lighter shaded region. The AE index (Fig. 4d) shows that auroral electrojet activity became stronger from 06:00 UT on 24 August 2005. Subsequent to this $B_{z}$ (Fig. 4b) continued to be directed northward before a rapid southward turning at 08:00 UT on 24 August. Figure 4e shows that the SYM-H index reached a maximum depression of $-175 \mathrm{nT}$ at 12:00 UT on 24 August, and then started to recover. Figure $4 \mathrm{c}$ shows that the $K_{p}$ index indicates that intense activity occurred on 24 August, reaching values of 9- in the time range 10:0012:00 UT. The $K_{p}$ and AE indices were observed to be quite low on 11 August and we have therefore used the ionospheric parameters from that day as the quiet time reference.

Figure 5 shows the deviations in the instrumental biases derived from GUAO relative to the mean (in TECU) from 9 August to 8 September (days 221-251) 2005 as a function of the DOY. The median values of the biases are evaluated

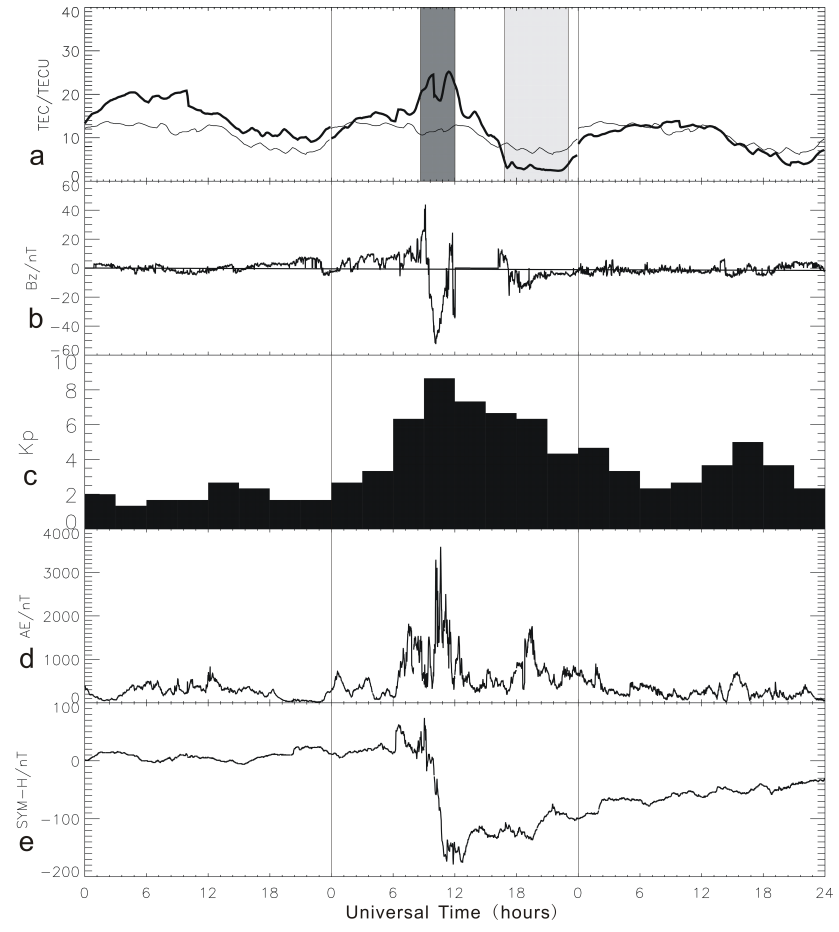

Fig. 4. (a) vertical TEC over GUAO station on 23-25 August (days 235-237) 2005 (bold line) and that on 11 August (day 223) 2005 (slim line). The darker shaded patch indicates the more than $100 \%$ increase positive phase of the storm, and the lighter shaded patch indicates the more than $50 \%$ decrease negative phase of the storm. (b) interplanetary magnetic field $B_{z}$, (c) $K_{p}$ index, (d) $\mathrm{AE}$ index, (e) $\mathrm{H}$ component of symmetric disturbance index on 23-25 August (days 235-237) 2005.

from the 31-day results centred on 24 August 2005 (the day of interest). Figure 5 uses the same scale for all the satellites and the $y$-axis range is from -12 TECU to 12 TECU, and the figure is separated into several panels to show the results clearly as Fig. 2. The deviations on day 236 are much larger for most of the satellites than those observed on the other days. The specific differences between the rBias and RMS are shown in Table 2.

Figure 6 shows the same information as for Fig. 3, but for the 24 August 2005 storm. It shows the temporal TEC variation curves derived from observations using the GUAO receiver over the period of the ionospheric storm. The PRN with the corresponding values for the difference between the rBias and RMS greater than 1 TECU are labelled in pink in the legend. The time ranges with darker and lighter shading are the same as those in Fig. 4a. Figure 6 shows that a larger number of GPS satellites showed significant deviations in the bias results in this event than in the 15 December 2006 event. 


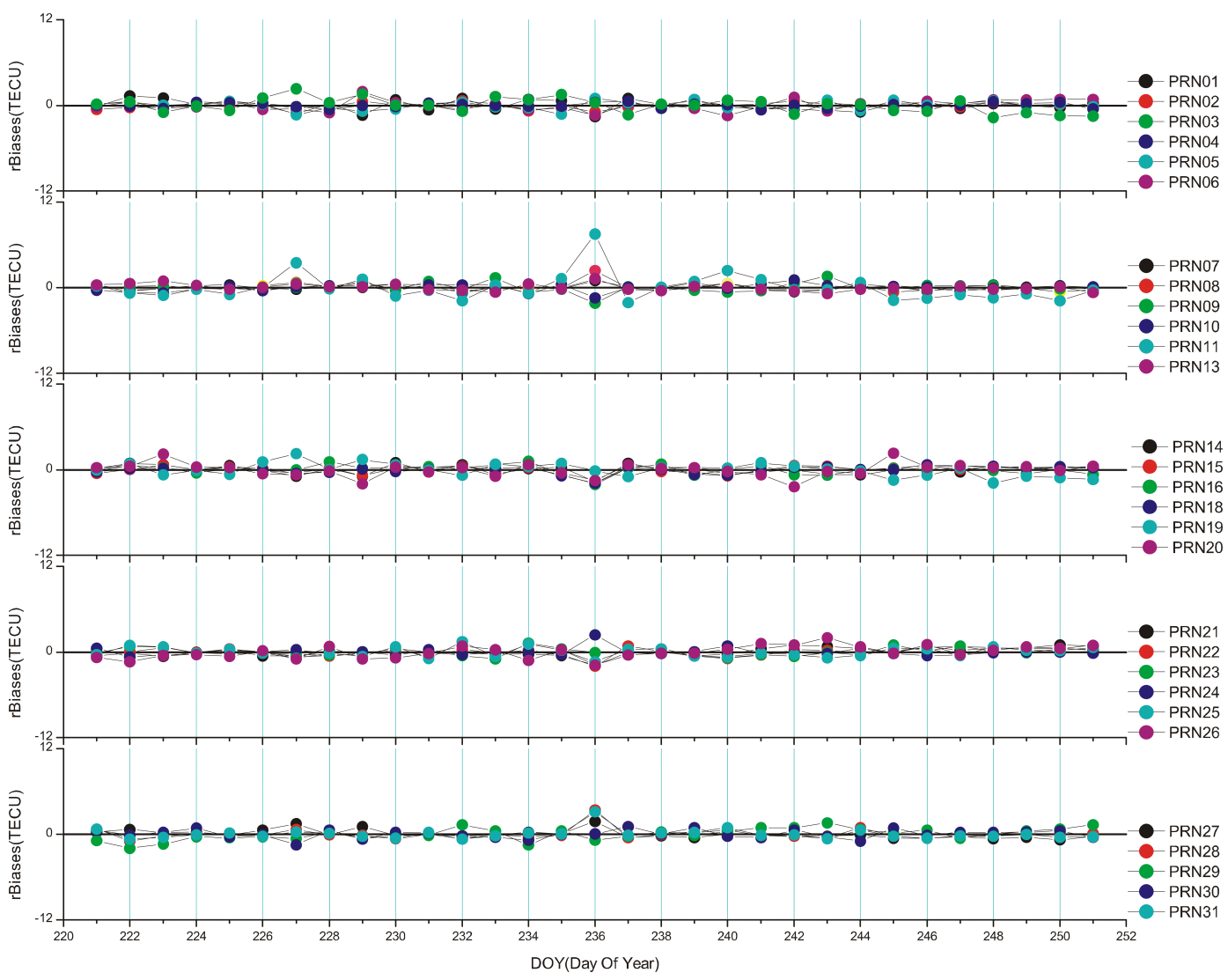

Fig. 5. The deviations in the instrumental biases derived from GUAO relative to the mean (in TECU) from 9 August to 8 September (days 221-251) 2005. They are divided into some panels to show the results clearly.

\subsection{The events of 8 and 10 November (days 313 and 315) 2004}

Figure 7 shows the derived vertical TEC (in TECU) over the BJFS station $\left(39.61^{\circ} \mathrm{N}, 115.89^{\circ} \mathrm{E}\right)$ (Fig. 7a), the interplanetary magnetic field $B_{z}$ (Fig. 7b), the $K_{p}$ index (Fig. 7c), the AE index (Fig. 7d), and the SYM-H index (Fig. 7e) over the period 7-11 November 2004. In Fig. 7a, the periods of the more than $100 \%$ increase positive storm phase and more than $50 \%$ decrease negative storm phase are marked by the darker and lighter shaded regions, respectively. The time intervals of interest are the obvious positive and negative periods on 8 and 10 November 2004. The period of the positive storm phase covers the time ranges 04:00 UT-21:00 UT on 8 November, and 02:00 UT-07:10 UT and 11:30 UT-16:10 UT on 10 November, while the negative storms occur over the periods of 08:30 UT-10:30 UT and 21:00 UT-22:30 UT on 10 November.

The 8 and 10 November 2004 events were caused by a super geomagnetic storm. The AE index (Fig. 7d) shows that auroral electrojet activity increased in strength from 16:00 UT on 7 November 2004 and maintained a high level until 20:00 UT on 10 November (except for a short interval

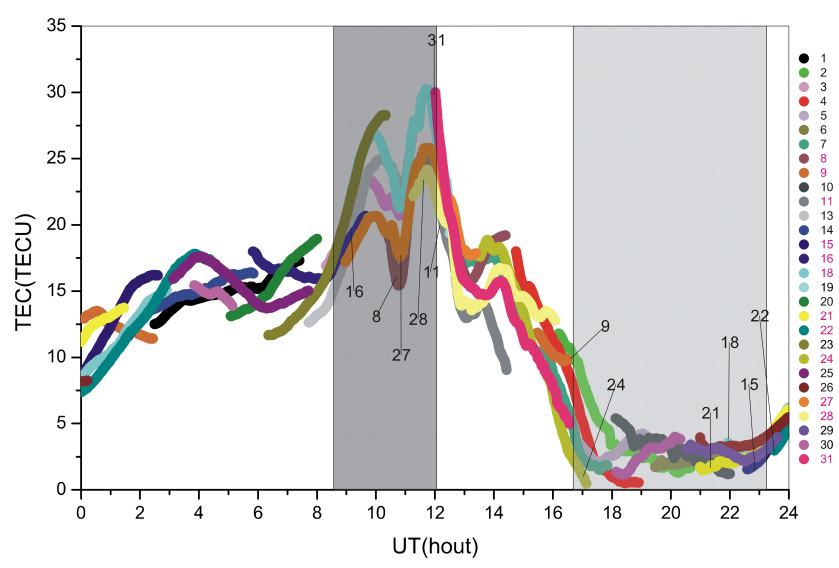

Fig. 6. The temporal TEC variation curves of all the GPS satellites from the GUAO receiver in the period of the ionospheric storm on 24 August 2005.

on 8 November). In the same period, $B_{z}$ (Fig. $7 \mathrm{~b}$ ) turned southward and remained in that direction for a relatively long period on both 8 November and 10 November. Over the same time range the SYM-H indices (Fig. 7e) reached maximum 
Table 3. The MEAN, RMS (Root Mean Square Value) and the difference between rBias and RMS of 29 GPS satellites in the event of the events of 8 and 10 November (days 313 and 315) 2004. The PRN column gives the number of the GPS satellite, and the MEAN column gives the median value of instrumental biases.

\begin{tabular}{|c|c|c|c|c|}
\hline PRN & $\begin{array}{r}\text { MEAN } \\
(\mathrm{TECU})\end{array}$ & $\begin{array}{r}\text { RMS } \\
(\mathrm{TECU})\end{array}$ & $\begin{array}{r}\text { rBiasRMS on } \\
8 \text { Nov (TECU) }\end{array}$ & $\begin{array}{l}\text { rBiasRMS on } \\
10 \text { Nov (TECU) }\end{array}$ \\
\hline 1 & 7.28 & 0.86 & -0.28 & 0.69 \\
\hline 3 & 6.34 & 1.12 & 3.83 & 0.43 \\
\hline 4 & 2.42 & 1.26 & 4.44 & 0.76 \\
\hline 5 & 5.26 & 1.35 & -0.19 & 2.85 \\
\hline 6 & 3.55 & 1.39 & 3.06 & 1.65 \\
\hline 7 & 10.16 & 1.38 & 1.66 & 3.59 \\
\hline 8 & 7.69 & 3.06 & 10.62 & 5.29 \\
\hline 9 & 2.59 & 1.29 & -1.04 & 5.15 \\
\hline 10 & 8.99 & 0.70 & 1.69 & 1.33 \\
\hline 11 & -7.37 & 1.40 & 2.94 & 1.55 \\
\hline 13 & -5.10 & 2.86 & 4.74 & 8.66 \\
\hline 14 & -6.26 & 1.35 & -0.26 & 4.66 \\
\hline 15 & 8.33 & 1.61 & -0.54 & 3.79 \\
\hline 16 & -3.26 & 0.92 & 1.76 & 0.78 \\
\hline 17 & 10.67 & 1.02 & 2.31 & 2.39 \\
\hline 18 & -5.34 & 1.32 & -0.61 & 4.52 \\
\hline 19 & -11.90 & 1.02 & 2.60 & 1.14 \\
\hline 20 & 1.81 & 3.06 & -0.68 & 11.44 \\
\hline 21 & -7.98 & 1.37 & 0.25 & 3.85 \\
\hline 22 & -19.70 & 1.31 & -0.13 & 4.40 \\
\hline 23 & -23.71 & 2.15 & 0.52 & 4.61 \\
\hline 24 & 11.40 & 0.64 & 0.37 & 1.56 \\
\hline 25 & -0.82 & 0.88 & -0.11 & 1.57 \\
\hline 26 & 1.97 & 1.05 & -0.05 & 4.03 \\
\hline 27 & 6.42 & 2.51 & 6.64 & 6.01 \\
\hline 28 & -4.37 & 1.07 & -0.69 & 2.15 \\
\hline 29 & 1.56 & 1.10 & 0.15 & 4.22 \\
\hline 30 & -2.55 & 1.27 & -1.06 & 3.56 \\
\hline 31 & 3.07 & 1.22 & 1.90 & 2.22 \\
\hline
\end{tabular}

depressions of $-394 \mathrm{nT}$ and $-282 \mathrm{nT}$ on 8 November and 10 November, respectively and then started to recover. Figure $7 \mathrm{c}$ shows the $K_{p}$ index, which demonstrates that intense activity occurred on 8 November, reaching values of 9- in the time range 00:00-06:00 UT. On 10 November, the $K_{p}$ index again showed a significant increase, reaching values of 9- for a period of about three hours. The $K_{p}$ and AE indices were observed to be quite low on 6 November and we have used the ionospheric parameters from 6 November as the quiet time reference.

Figure 8 illustrates the deviations in the instrumental biases derived from BJFS relative to the mean (in TECU) during the period 24 October to 23 November (days 298-328) 2004 as a function of the DOY. The median values of the biases are evaluated from the 31-day results centred on 8 November 2004 (one of the ionospheric storm days of interest). Figure 8 uses the same scale for all the satellites and the $y$-axis range is from -12 TECU to 12 TECU, and the figure is separated into several panels to show the results clearly

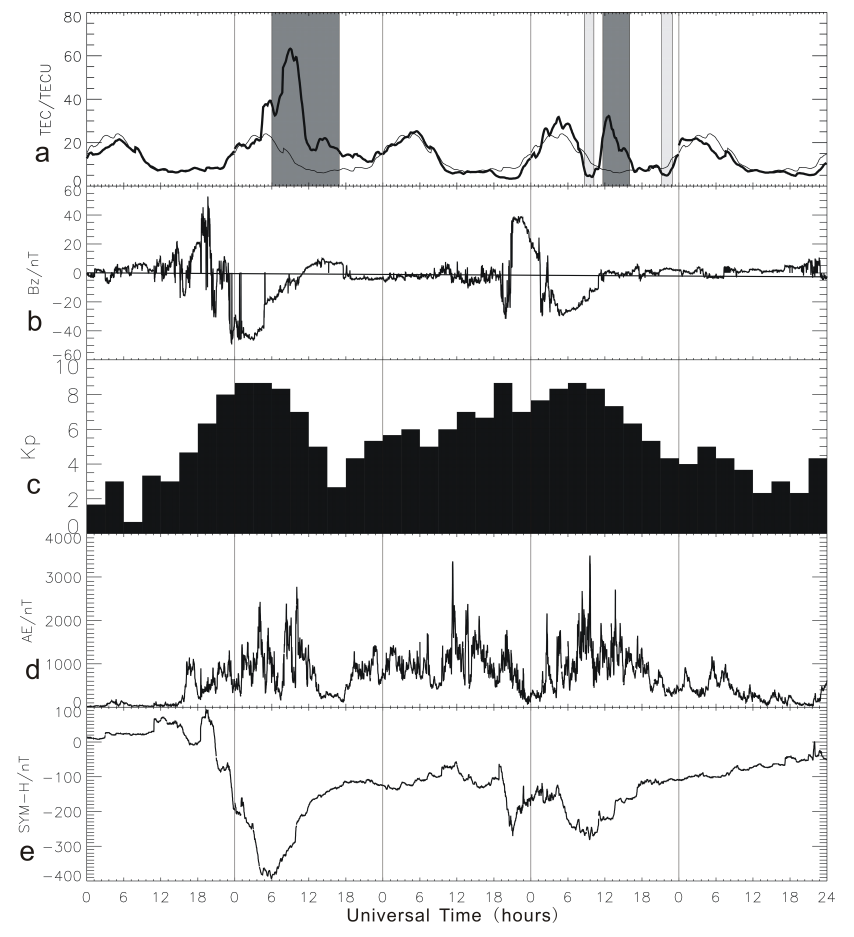

Fig. 7. (a) vertical TEC over BJFS station from 7 to 11 November (days 312 and 316) 2004 (bold line) and that on 6 November (day 311) 2004 (slim line). The darker shaded patch indicates the more than $100 \%$ increase positive phase of the storm, and the lighter shaded patch indicates the more than $50 \%$ decrease negative phase of the storm. (b) interplanetary magnetic field $B_{z}$, (c) $K_{p}$ index, (d) $\mathrm{AE}$ index, (e) $\mathrm{H}$ component of symmetric disturbance index from 7 and 11 November (days 312 and 316) 2004.

as Fig. 2. The deviations on day 313 are much larger in most of the satellites, and those on day 315 are all larger than the alternative RMSs. The specific differences between the rBias and RMS are shown in Table 3.

Figures 9 and 10 show the same information as in Fig. 3, but for 8 November and 10 November 2004, respectively. Figures 9 and 10 illustrate the temporal TEC variation curves derived from observations from the BJFS receiver over the period of two consecutive ionospheric storms. The time ranges with darker and lighter shading are the same as those in Fig. 7a. Figure 9 shows that most of the bias results where the GPS satellites deviate significantly occur in the area with dark shading (similar to Fig. 3). For 10 November all of the bias results from the GPS satellites deviated significantly for this unusual double-peak-shaped event: one of the two peaks emerged in the evening (local time). Note that ionospheric scintillations in electromagnetic waves occurred at approximately 14:00 UT on 10 November and these may be why the observed deviation in the instrumental biases was so large. 


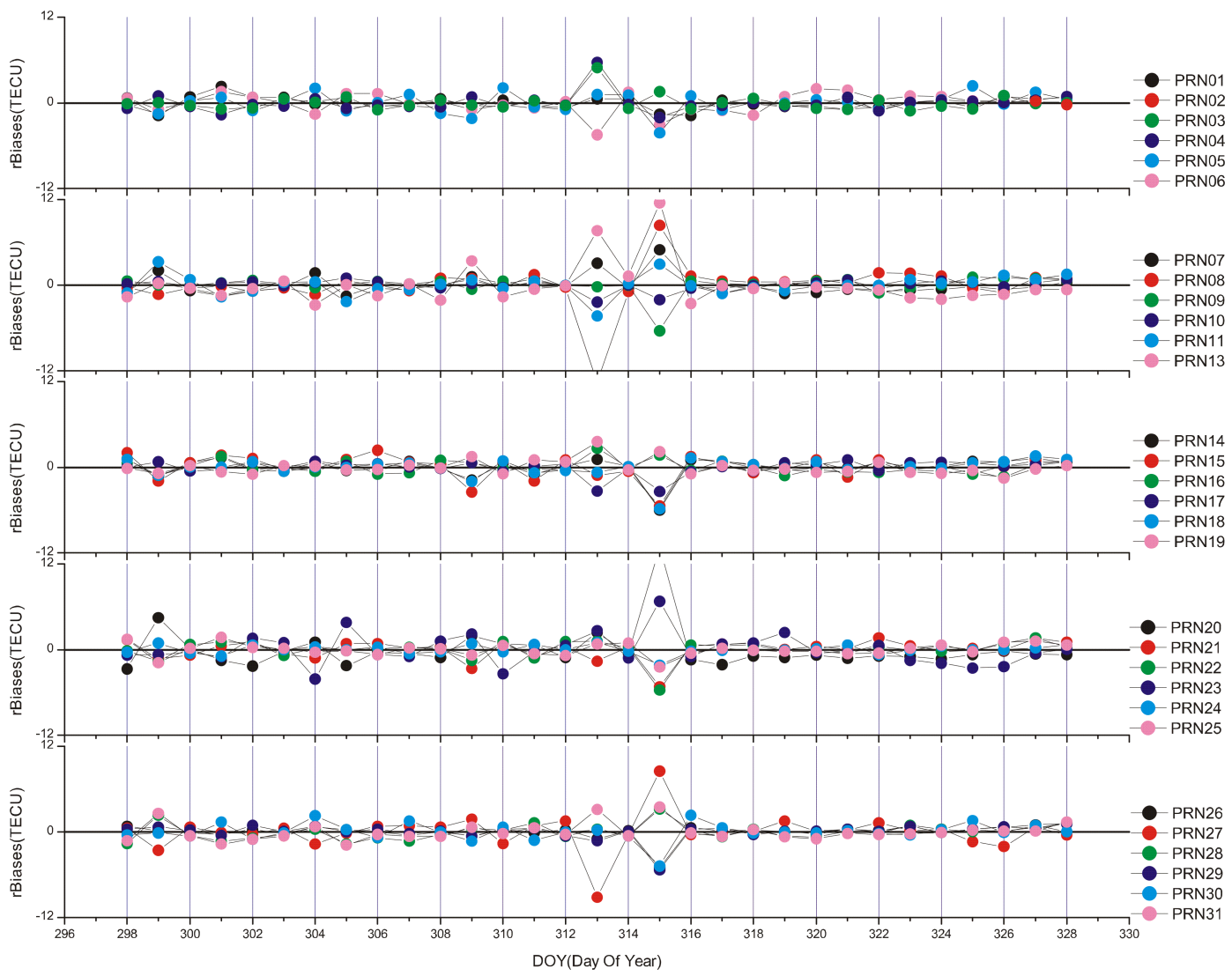

Fig. 8. The deviations in the instrumental biases derived from BJFS relative to the mean (in TECU) during the period 24 October to 23 November (days 298-328) 2004. They are divided into some panels to show the results clearly.

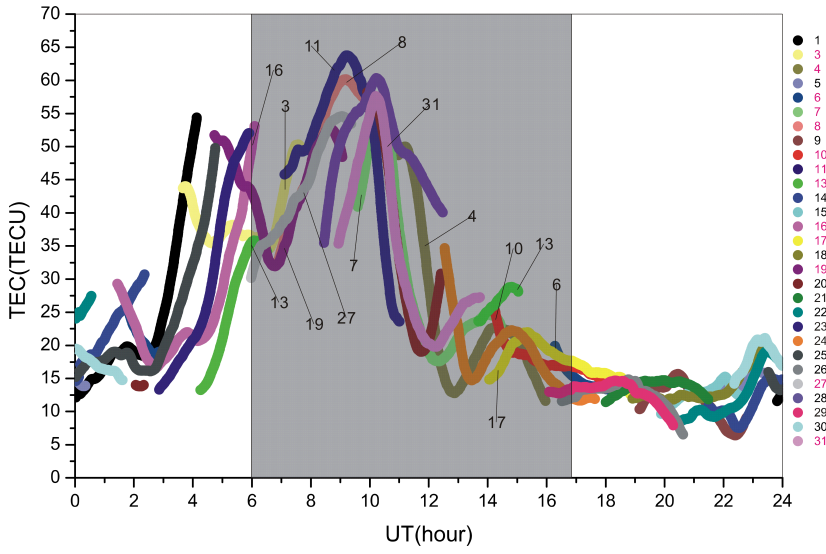

Fig. 9. The temporal TEC variation curves of all the GPS satellites from the BJFS receiver in the period of the ionospheric storm on 8 November 2004.

\section{Discussion and conclusions}

The deviations in the TEC between the quiet times and the ionospheric storm times (induced by geomagnetic storms) resulted in severe fluctuations in the derived GPS instru-

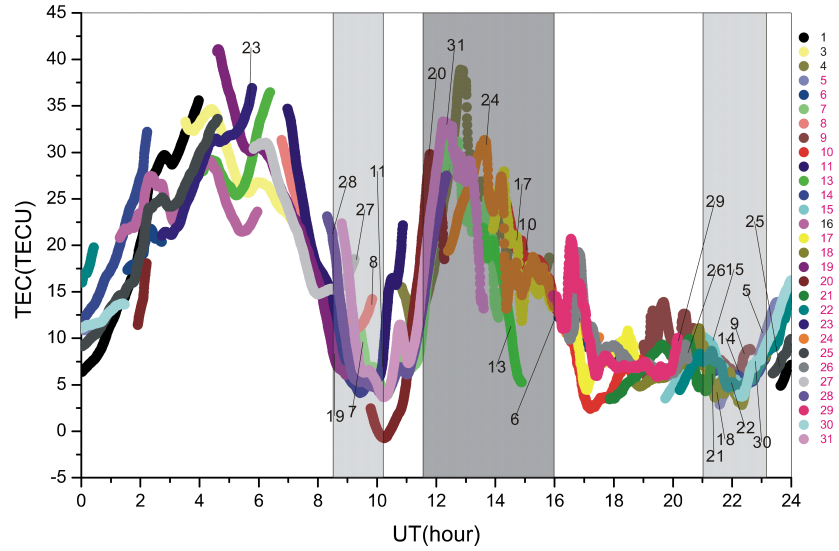

Fig. 10. The temporal TEC variation curves of all the GPS satellites from the BJFS receiver in the period of the ionospheric storm on 10 November 2004.

mental biases. When the elevations were limited to being greater than some value (here $30^{\circ}$ ), to remove dubious data, the distribution range of the ionospheric pierce points was confined to approximately $10^{\circ}$ in both latitude and longitude. In Eq. (9) an event only influences those equations 
corresponding to the same latitude and the same local time as the event (each equation covers a latitude range of $0.5 \mathrm{de}-$ grees and duration of $0.1 \mathrm{~h}$ as mentioned in Sect. 2.2). "The same local time" in an equation established in this way corresponds to those times for which the difference is less than 0.7 UT hours $\left(10^{\circ} / 15^{\circ}\right)$. If storm-induced TEC deviations occur over a small interval, the timescale over which the influence is observed extends (in the worst-case scenario) from $0.7 \mathrm{~h}$ before the beginning of the interval to $0.7 \mathrm{~h}$ after it ends.

First, we quantify a severe ionospheric storm as more than $100 \%$ increase positive storm phase and more than $50 \%$ decrease negative storm phase. As shown in Fig. 3 for the event on 15 December (day 349) 2006, severe TEC deviations induced by the positive storm lasted for only a few hours; in particular the deviations reached up to $100 \%$ increase for a period of approximately two hours. At other times during the positive storm, and for the entire duration of the negative storm, the TEC deviations were less severe. This means that only the instrumental biases of GPS satellites observed during the short interval when the storm was severe were influenced (quantified as rBias-RMS $>1$ TECU). However, not all the instrumental biases of satellites in the darker shading were influenced. Second, if we quantify the general ionospheric storm as more than $20 \%$ increase positive storm phase and more than $20 \%$ decrease negative storm phase and consider the influenced instrumental biases as (rBias $>$ RMS), we acquire the same result, in which some satellites located in the storm intervals (not indicated by shading) were influenced, but others were not. Possible explanations of this phenomenon are that the assumption errors in two or more satellites may construct one or more accurate equations as Eq. (8), or that very few constructed equations are based on data in the severe intervals (satellites were also observed outside the storm period).

Figure 6 shows the event of 24 August (day 236) 2005. The severe positive storm duration was longer than that for the 15 December 2006 event and there was a period of more than three and half hours when the deviations in the TEC exceeded $100 \%$ increase. In addition, the deviations in the TEC induced by the negative storm were also larger than those for the 15 December 2006 event, and for a period of approximately seven hours the deviations in the TEC exceeded 50\% decrease. Also, the influenced instrumental biases (rBiasRMS $>1$ TECU) were all located in the interval of the severe ionospheric storm. Because of the severe storm, the consequences of this are that the number of GPS satellites having their instrumental biases influenced by the storm is greater for the 24 August 2005 event than for the 15 December 2006 event. As for the quantified general storms of more than $20 \%$ increase positive storm phase and more than $20 \%$ decrease negative storm phase, we acquired the same result as the 15 December 2006 event, where some satellites located in the storm intervals (not indicated by shading) were influenced, but others were not.
Figures 9 and 10 show the events of 8 and 10 November (days 313 and 315) 2004. In Fig. 9, the more than 100\% increase severe positive storm lasted for more than ten hours, so most satellites were influenced. In Fig. 10, positive and negative storms were observed to alternate and also to occur in the evening. The TEC deviated up to $100 \%$ increase and more than $50 \%$ decrease from the quiet time value for a period of nine hours. In Figs. 9 and 10, the influenced instrumental biases (rBias-RMS $>1$ TECU) were all located in the interval of the severe ionospheric storm except for the satellite PRN 23 in Fig. 10. The time interval when satellite PRN 23 was observed was also located in the period of a large ionospheric storm, although the intensity did not reach $100 \%$ increase. The storm also produced ionospheric scintillation, and in the period up to 18:00 UT there were obvious fluctuations caused by scintillations. It is beyond the scope of this paper to analyze the instrumental bias deviations caused by ionospheric scintillation because of a lack of data and errors in the navigation files. In addition, if we quantify the general ionospheric storms as more than $20 \%$ increase positive storm phase and more than $20 \%$ decrease negative storm phase, we acquired the same result as the 15 December 2006 event in which some satellites located in the long storm intervals (not indicated by shading) were influenced, but others were not. Therefore, the observations during the severe storm period were not sufficient but were a necessary condition for a satellite to have a large deviation in its instrumental biases. Furthermore, there may be other conditions to explain the large deviation of PRN 23 on 10 November 2006, such as the total number of observations of the satellite, the maximum elevation during the whole day, or some instrumental error in the satellite itself.

Based on the results derived from the single-station method we have developed, we conclude that different types of ionospheric storms exert a variety of influences on the derived instrumental biases that are determined for GPS satellites and receivers. Since the influence of a storm can last for some time, it is necessary that the instrumental biases be determined from data on adjacent quiet days to obtain accurate estimates of the ionospheric TEC.

Acknowledgements. We would like to thank the SOPAC (http: //sopac.ucsd.edu/cgi-bin/dbDataBySite.cgi) for providing the GPS data. The China NSFC (grants: 40674089, 40636032) and China NRBI (grant: 2006CB806306) jointly supported this work.

Topical Editor M. Pinnock thanks L. Liu and another anonymous referee for their help in evaluating this paper.

\section{References}

Araujo-Pradere, E. A., Fuller-Rowell, T. J., and Codrescu, M. V.: STORM: An empirical storm-time ionospheric correction model, 1, Model description, Radio Sci., 37(5), 1070, doi:10.1029/2001RS002467, 2002a. 
Araujo-Pradere, E. A. and Fuller-Rowell, T. J.: STORM: An empirical storm-time ionospheric correction model, 2, Validation, Radio Sci., 37(5), 1071, doi:10.1029/2002RS002620, 2002b.

Araujo-Pradere, E. A., Fuller-Rowell, T. J., and Bilitza, D.: Time Empirical Ionospheric Correction Model (STORM) response in IRI2000 and challenges for empirical modelling in the future, Radio Sci., 39, RS1S24, doi:10.1029/2002RS002805, 2004.

Bishop, G., Mazzella, A., Holland, E., and Rao, S.: Algorithms that use the ionosphere to control GPS errors, in proceedings of the IEEE 1996 Position, Location and Navigation Symposium (PLANS), 145-152, IEEE Press, Piscataway, N.J., 1996.

Brunini, C., Meza, A., and Bosch, W.: Temporal and spatial variability of the bias between TOPEX- and GPS-derived total electron content, J. Geodesy, 79, 175-188, doi:10.1007/s00190-0050448-z, 2005.

Buonsanto, M. J.: Ionospheric storms - A review, Space Sci. Rev., 88, 563-601, 1999.

Calais, E. and Minster, J. B.: GPS detection of ionospheric perturbations following a Space Shuttle ascent, Geophys. Res. Lett., 23, 1897-1900, 1996.

Chang, Q., Zhang, D. H., Xiao, Z., and Zhang, Q. S.: A method for estimating GPS instrumental biases and its application in TEC calculation, Chinese J. Geophys.-Ch., 44(5), 596-601, 2001.

Ciraolo, L., Azpilicueta, F., Brunini, C., Meze, A., and Radicella, S. M.: Calibration errors on experimental slant total electron content (TEC) determined with GPS, J. Geodesy, 81, 111-120, doi:10.1007/s00190-006-0093-1, 2007.

Coco, D. S., Coker, C., Dahlke, S. R., and Clynch, J. R.: Variability of GPS satellite differential group delay biases, IEEE T. Aero. Elec. Sys., 27, 931-938, 1991.

Ducic, V., Artru, J., and Lognonne, P.: Ionospheric remote sensing of the Denali Earthquake Rayleigh surface waves, Geophys. Res. Lett., 30, 1951, doi:10.1029/2003GL017812, 2003.

Goncharenko, L. P., Foster, J., Coster, A., Huang, C., Aponte, N., and Paxton, L.: Observations of a positive storm phase on September 10, 2005, J. Atmos. Sol.-Terr. Phys., 69, 1253-1272, 2007.

Ho, C. M., Wilson, B. D., Mannucci, A. J., Lindqwister, U. J., and Yuan, D. N.: A comparative study of ionospheric total electron content measurements using global ionospheric maps of GPS, TOPEX radar, and the Bent model, Radio Sci., 32, 1499-1521, 1997

Hovath, I. and Essex, E. A.: Using observations from the GPS and TOPEX satellites to investigate night-time TEC enhancements at mid-latitudes in the southern hemisphere during a low sunspot number period, J. Atmos. Sol.-Terr. Phys., 62, 371-391, 2000.

Iyemori, T. and Rao, D. R. K.: Decay of the Dst field of geomagnetic disturbance after substorm onset and its implication to storm-substorm relation, Ann. Geophys., 14, 608-618, 1996, http://www.ann-geophys.net/14/608/1996/.

Lanyi, G. E. and Roth, T.: A comparison of mapped and measured total ionospheric electron content using Global Positioning System and beacon satellites observations, Radio Sci., 23, 483-492, 1988.

Liu, L., Wan W., Lee, C. C., Ning, B., and Liu, J. Y.: The low latitude ionospheric effects of the April 2000 magnetic storm near 120_E, Earth Planets Space, 56, 607-612, 2004.

Liu, Z. Z. and Gao, Y.: Ionospheric TEC predictions over a local area GPS reference network, GPS Solut., 8, 23-29, 2004.
Ma, G. and Maruyama, T.: Derivation of TEC and estimation of instrumental biases from GEONET in Japan, Ann. Geophys., 21, 2083-2093, 2003, http://www.ann-geophys.net/21/2083/2003/.

Mannucci, A. J., Wilson, B. D., Yuan, D. N., Ho, C. H., Lindqwister, U. J., and Runge, T. F.: A global mapping technique for GPSderived ionospheric electron content measurements, Radio Sci., 33, 565-582, 1998.

Mendillo, M., Lin, B., and Aarons, J.: The application of GPS observations to equatorial aeronomy, Radio Sci., 35, 885-904, 2000.

Mendillo, M.: Storms in the ionosphere: Patterns and processes for total electron content, Rev. Geophys., 44, RG4001, doi:10.1029/2005RG000193, 2006.

Nishioka, M., Saito, A., and Tsugawa, T.: Occurrence characteristics of plasma bubble derived from global ground-based GPS receiver networks, J. Geophys. Res., 113, A05301, doi:10.1029/2007JA012605, 2008.

Otsuka, Y., Ogawa, T., Saito, A., Tsugawa, T., Fukao, S., and Miyazaki, S.: A new technique for mapping of total electron content using GPS network in Japan, Earth Planets Space, 54, 63-70, 2002.

Press, W. H., Teukolsky, S. A., Vetterling, W. T., and Flannery, B. P.: Numerical Recipes in Fortran 77, Cambridge University Press, 670-673, 1992.

Prolss, G. W.: Ionospheric F-region storms, in: Handbook of Atmospheric Electrodynamics, edited by: Volland, H., 195-247, CRC Press, Boca Raton, Fla, 1995.

Sardón, E. and Zarraoa, N.: Estimation of total electron content using GPS data: How stable are the differential satellite and receiver instrumental biases?, Radio Sci., 32, 1899-1910, 1997.

Vladimer, J. A., Lee, M. C., Doherty, P. H., Decker, D. T., and Anderson, D. N.: Comparisons of TOPEX and Global Positioning System total electron content measurements at equatorial anomaly latitudes, Radio Sci., 32, 2209-2220, 1997.

Wells, D., Beck, N., Delikaraoglou, D., Kleusberg, A., Krakiwsky, E. J., Lachapelle, G., Langley, R. B., Nakiboglu, M., Schwarz, K., Tranquilla, J. M., and Vanicek, P.: Guide to GPS Positioning, Fredericton, New Brunswick, Canada: Canadian GPS Associates, 1986

Wilson, B. D., Mannucci, A. J., and Edwards, C. D.: Subdaily northern hemisphere ionospheric maps using an extensive network of GPS receivers, Radio Sci., 30, 639-648, 1995.

Yizengaw, E., Dyson, P. L., Essex, E. A., and Moldwin, M. B.: Ionosphere dynamics over the Southern Hemisphere during the 31 March 2001 severe magnetic storm using multi-instrument measurement data, Ann. Geophys., 23, 707-721, 2005, http://www.ann-geophys.net/23/707/2005/.

Zhang, D. H. and Xiao, Z.: Study of the ionospheric total electron content response to the great flare on 15 April 2001 using the International GPS Service network for the whole sunlit hemisphere, J. Geophys. Res., 108(A8), 1330, doi:10.1029/2002JA009822, 2003.

Zhang, D. H. and Xiao, Z.: Study of ionospheric response to the 4B flare on 28 October 2003 using International GPS Service network data, J. Geophys. Res., 110, A03307, doi:1029/2004JA010738, 2005. 